\title{
A NEOLOGIA LITERÁRIA NO UNIVERSO POÉTICO DE FERREIRA GULLAR: UMA LEITURA DE NEOLOGISMOS
}

\section{THE LITERARY NEOLOGISM IN THE FERREIRA GULLAR POETIC UNIVERSE: A READING OF NEOLOGISMS}

\author{
Luís Henrique Serra ${ }^{1}$ \\ Universidade Federal do Maranhão
}

\section{RESUMO}

Este é uma investigação no universo poético de Ferreira Gullar e de como o poeta utilizava-se da neologia literária para a construção de sentidos próprios. Investiga-se se os diferentes tipos de neologismos podem ser encontrados no universo poético de Ferreira Gullar e os sentidos que podem ser decorridos dessa escolha léxica. Nesse sentido, o trabalho baseia nas propostas de Barbosa (2001), Alves (2007), Cabré (2012) e Cardoso (2012), que discutem o neologismo como um fenômeno das línguas naturais, além do neologismo literário como uma forma específica de neologismos. Nesta investigação, buscou-se em sua primeira fase produtiva (a experimentalista) para observar qual o papel das construções neológicas na construção de sentidos e na sua relação com o mundo do eu-lírico gullariano.

PALAVRAS-CHAVE: Neologismo Literário. Ferreira Gullar. Expressividade.

\begin{abstract}
This is a research in poetic Ferreira Gullar universe and how the poet used the literary neologism to build self senses. It investigates if the different kinds of neologisms can be finding in Ferreira Gullar universe and the senses that can be finding from this lexical choice. By this way, this work is based in Barbosa (2001), Alves (2007), Cabré (2012) and Cardoso (2012) propositions. Theses authors discuss the neologism as a natural linguistic phenomenon, they discuss also the literary neologism as a kind of neologism. In this research, it seeks, in his first productive phase (the experimentalist,) to observe what is the role of neologisms in the Gullar i-lyrical construction of meaning and in her relationship with the world.
\end{abstract}

KEY-WORDS: Literary Neologism. Ferreira Gullar. Expressivity

\section{INTRODUÇÃO}

Quando se pensa em experimentalismo na poesia brasileira, sem dúvidas, o poeta maranhense Ferreira Gullar é um dos que mais se destaca. Ao longo de sua carreira poética, Ferreira Gullar fez inúmeros experimentos com a linguagem, no que resultou em formas bastante diferente do que se espera em poesia. Gullar alçou a poesia a voos nunca dantes tentados, o que muitas vezes o fez ser incompreendido, dada a força abstrata e conceitual de seus poemas. Não se pode esquecer que Gullar, junto com artistas como Lygia Clark, Almicar de Castro, Franz Weissemann entre outros, lançou o manifesto (e o movimento) neoconcreto, que pregava uma integração entre a linguagem, a arte (A Literatura) e a forma concreta. O movimento, quanto à poesia, defendia que deveria haver a subversão da ordem imposta, mudando, inclusive, a ordem sintática do verso e da palavra. Essas

${ }_{1}^{1}$ Mestre em Letras (Filologia e Língua Portuguesa) e doutorando em Letras (Filologia e Língua Portuguesa) pela Universidade de São Paulo. luis.ufma@gmail.com

Revista do GELNE, Natal/RN, Vol. 20 - Número 1: p. 136-149. 2018 
experimentações fizeram com que a poesia gullariana possuísse muitas faces e nuances.

Nesse sentido, a poesia Gullariana sofreu inúmeras transformações, tendo mudado de uma poesia mais 'comportada', no seu livro Um pouco acima do chão (1949), para uma poesia mais experimentalista em $A$ Luta Corporal (1954), onde o poeta arrisca-se em uma viagem sem retorno a uma linguagem completamente diferente da de seus primeiros versos. Cumpre lembrar, de igual modo, que Gullar, além dos versos neoconcretos, escreveu poesia de cordel e poesia rimada, simplificada, poesia metrificada marcando seu percurso poético com inúmeras mudanças de posição poético-conceitual.

As mudanças operadas por Gullar deixaram um mundo neológico extremamente curioso e fantástico para se investigar. Desse modo, este estudo é uma investigação da poesia de Ferreira Gullar e seu percurso poético neológico. Investigam-se as construções neológicas feitas pelo poeta maranhense em sua poesia de suas primeiras duas fases de produção poética. Objetiva-se, em primeiro lugar, flagrar os neologismos literários criados por Gullar ao longo de toda a sua poesia e observar também os aspectos estilísticos dela, notar como essas criações carregam em si conteúdos específicos do universo gullariano. Em outro momento, observa-se como esse neologismo marca as concepções estéticas e literárias do poeta em suas manifestações poéticas.

Sendo assim, num primeiro momento, tratar-se da neologia e da neologia literária, um tipo especial de neologia que surge a partir do estilo e do sentido do texto literário; num segundo momento, será apresentada a metodologia utilizada neste estudo e como foi feita a recolha dos poemas analisados; seguidamente, observam-se e comentam-se os neologismos literários criados por Ferreira Gullar em sua poesia. Por fim, apresentam-se as considerações finais deste estudo, bem como as referências utilizadas para a sua elaboração.

\section{Neologia: a neologia literária ou estilística}

A língua é um organismo vivo que possui suas 'fases', ou seja, os elementos linguísticos, em analogia aos seres vivos, nascem, crescem, reproduzem-se e morrem. Essa é só uma forma de observar os diferentes fenômenos linguísticos apresentados na língua natural. Quando se diz que os elementos da língua nascem, estamos em um âmbito bastante produtivo das línguas naturais. A língua, para cumprir seu papel de instrumento de comunicação (A língua é um dos [principais] elementos da linguagem, já diria Saussure), precisa adaptar-se às necessidades dos falantes, tendo que, a todo o momento, criar e 'excluir' elementos da língua. É como afirma Alves (2007, p. 5): “O acervo lexical de todas as línguas se renova. Enquanto que umas palavras deixam de ser utilizadas e tornam-se arcaicas, outra grande quantidade de unidades lexicais é criada pelos falantes". Esse processo de criação de elementos linguísticos, chamado de neologia, dar-se não só por motivos estritamente internos das línguas, como é próprio dos sistemas, mas também por motivos exteriores, ou de outros sistemas. Ainda conforme Alves:

O neologismo pode ser formado por mecanismos oriundos da própria língua, os processos autóctones, ou por itens léxicos provenientes de outros sistemas linguísticos. Na língua portuguesa, os dois recursos têm sido amplamente empregados, diacrônica e sincronicamente. (ALVES, 2007, p. 5)

Conhecer esses processos e como eles acontecem, além de saber quais são os fatores que os condicionam são tarefas para a Neologia que, segundo Cabré, consiste em um

Campo de conocimiento y de trabajo que se ocupa de los fenómenos nuevos que aparecen en las lenguas. En tanto que campo de reflexión teórica, intenta dar respuestas a temas como qué se entiende por neologismo, cuáles son estrategias que utilizan los hablantes para actualizar su léxico, cómo se adquiren estas nuevas unidades, como se caracterizan gramatical y pragmaticamente o cómo se relacionan con las unidades léxicas ya existentes, etc. (CABRÉ, 2010, p. 13) 
O neologismo, objeto de estudo da Neologia, tem inúmeros características, isto é, pode se dar em distintos níveis da língua. Desse modo, neologismo pode ser uma palavra nova, ou ainda, pode ser uma nova acepção dada a uma já existente; além disso, o neologismo pode ser uma palavra que é tomada de um outro sistema linguístico e empregada com bastante regularidade dentro de um sistema léxico diferente. Cumpre salientar que um neologismo é um elemento do sistema linguístico que sofre um processo de adaptação, e que está atrelado ao tempo, desse modo, é seu tempo de entrada e adaptação que baseia sua característica neológica: esse processo possui três momentos que consistem na (i) iniciação neológica ou início do processo de neologização, isto é, quando um elemento lexical recebe uma atribuição ou um significado novo dentro do sistema conceitual; (ii) o segundo momento é o (ii)início da desneologização, que consiste na aceitação e no uso daquela unidade lexical recém criada ou adotada; por conseguinte, o (iii) final da neologização, ou seja, quando o significado e o elemento lexical já é cotidianamente adotado pela sociedade. Cardoso(2013) complementa:

(...)um neologismo não existe realmente se não for aceito e utilizado pelo menos por um certo número de interlocutores. O neologismo virtual se torna efetivo em um ato de fala. Sua frequência pode ir crescendo ao longo do tempo, dependendo de sua aceitabilidade, e pode chegar a integrar a norma, passando por um processo de desneologização. (CARDOSO, 2013, p 16)

Desse modo, a unidade neológica pode resultar, segundo Cardoso(2013), de um significante com um novo significado, de uma alteração no plano do significante que altere seu sentido, de uma alteração no plano do significado sem a alteração do significante, de uma transformação sintagmática em que não há mudança de estrutura, mas ajuntamento inédito de elementos; além da importação de um vocábulo que pertença a um outro sistema linguístico. Observando os modos em que o neologismo se apresenta, Cardoso(2013), Alves (2007), Barbosa (2001), Guilbert (1975) entre outros estudiosos consideram quatro formas de neologismos, ou, como afirma Barbosa (2001, p. 40), quatro mecanismos linguísticos que definem “(...) uma tipologia de processos instauradores do neologismo”: o neologismo fonológico, o neologismo semântico, o neologismo sintagmático e o neologismo alogenético ou por empréstimo.

O neologismo fonológico seria a criação de um elemento inédito fonológica e foneticamente falando, isto é, uma combinação de sons e/ou sílabas inédita. Para Alves (2007), o neologismo fonológico consiste em um elemento do léxico totalmente inédito, que tenha sido criado sem possuir alguma base pré-existente na língua. A autora lembra que criações desse tipo são extremamente raras na língua geral. Barbosa (2001) e Cardoso(2013) dividem o neologismo fonológico em duas subclasses: a ex-nibilo e a onomatopaica. A ex-nibilo é a formação sem precedentes, inédita, é o neologismo fonológico inédito, apresentando por Alves (idem. cit.); o neologismo fonológico onomatopaico já não é tão inédito quando o ex-nibilo, pois ele sempre tem alguma relação com algum som ou ruído do ambiente, ele é, portanto, semi-arbitrário.

O neologismo semântico consiste na atribuição de um novo significado a um elemento (significante) já existente, ou como afirma Cardoso (2013, p 18), "pode ser definida pelo aparecimento de uma nova significação conferida a um mesmo segmento fonológico." Ou seja, o neologismo semântico resulta da alteração, no plano do significado, de algum sema que constitui uma unidade sêmica. Desse modo, as metáforas e as metonímias são responsáveis pela criação de neologismos semânticos.

O neologismo sintagmático é a junção de elementos já existentes no léxico, podendo ser esses elementos completos ou não semanticamente falando. Cardoso (2013) afirma que, muitas vezes, essas construções podem ser estranhas, formas inesperadas, causando um estranhamento que contribui "por mobilizar a memória, o imaginário, os desejos do receptor, conduzindo-o à percepção de outros pontos de vista sobre o mundo" (CARDOSO, 2013, p 52). Nesse sentido, o neologismo

Revista do GELNE, Natal/RN, Vol. 20 - Número 1: p. 136-149. 2018 
sintagmático pode acontecer a partir de fenômenos como a composição e a derivação e suas especificações, isto é, portanto, neologia por prefixação ou por sufixação, composição por justaposição ou por aglutinação e etc. Barbosa(2001) lembra que o neologismo sintagmático:

É assim denominado, seja por resultado da interação, em forma de lexia - unidade lexical memorizada e disponível para atualização - de um segmento de frase, pontos iniciais de seu percurso, numa perspectiva gerativo-transformacional, seja por apresentarem, em sua estrutura, a combinatória lexicalizada de signos mínimos e de vocábulos autônomos. (BARBOSA, 2001, p 41)

O neologismo alogenético ou por empréstimo consiste no empréstimo ou utilização de um elemento estranho ao sistema. "Trata-se de um transplante de um vocábulo criado em outro sistema linguístico, de acordo com suas regras fonéticas, sintáticas e semânticas” (CARDOSO, 2013, p 19). Uma criação neológica estilista compreende várias etapas que vão desde a entrada do elemento alogenético no léxico até sua adaptação morfofonológicas ao sistema ao qual ele se adjunge.

A partir dessa tipologia, é possível analisar (como fazem os Observatórios Neológicos), investigar e ver a incidência do fenômeno neológico nas línguas naturais em seus diferentes meios de usos. Desse modo, é possível observar a neologia em textos acadêmicos, na língua falada, em textos de divulgação, em textos jornalísticos, em textos técnicos de diferentes níveis e em textos literários. Nesse sentido, é válido o dizer de Barbosa (2001, p 47), para quem a neologia pode caracterizar um tipo de universo discursivo,

Cada universo de discurso, entendido como classes de discursos, como norma discursiva, tem marcas fonético-fonológicas, morfossintáticas, semântico-sintaxicas e pragmáticas próprias. Algumas são comuns a vários universos de discurso, outras, exclusivas e caracterizadoras. O tipo preferencial de criação de novas unidades lexicais (...) pode ser uma dessas marcas, constituindo critérios bastante relevante para o delineamento estrutural de um domínio da experiência humana.

Destaca-se, como faz Cardoso (2010) a partir de estudos feitos em Guilbert (1975), que há dois tipos de neologismos lexicais: o neologismo denominativo e o neologismo literário (ou estilístico). O denominativo está ligado à conceptualização de elementos e de fenômenos novos na sociedade, já o literário não, está ligado a uma necessidade pessoal de um autor de textos, sejam eles literários ou não. Atrelado ao neologismo literário encontra-se a visão de mundo de um individuo, que deseja expressar-se contra ou a favor de um modelo pré-estabelecido. O autor, sentindo a necessidade de expressar suas ideias e formas de ver o mundo de uma maneira diferente, cria palavras novas, formas linguísticas novas que atendam a sua necessidade expressiva. Nesse sentido, sobre a neologia literária, Cardoso afirma:

Trata-se da forma de criação poética pela qual se pode fabricar uma nova lexia ou dar a uma lexia já formada uma significação diferente do sentido amplo e conhecido. Essa forma de criação está ligada à originalidade de expressão do individuo criador, à sua facilidade para criar, à sua facilidade para criar, à sua liberdade de expressão, deixando de lado os modelos já conhecidos ou até mesmo, indo contra eles. Esse tipo de criação, diz Guilbert (1975, p 41), é próprio de todos aqueles que têm alguma coisa a dizer e querem usar, para isso, suas próprias palavras, suas combinações de palavras. (CARDOSO, 2010, p. 231)

Desse modo, diferente do neologismo da língua geral, o neologismo literário tem um caráter propriamente subjetivo, o falante utiliza-se de processos vernaculares para formar unidades lexicais totalmente diferente da que se concebe normalmente, é uma lúcida construção de palavras, cujo o objetivo é a expressão nova ou particular. Com isso, é possível observar, no neologismo literário, formas complexas, jamais esperadas, criadas a partir de processos como composição e derivação, como os neologismos "acabarcomeçar", "dromerdário", "exgoto", "jornalário", "merdário”, criações de 
Haroldo de Campos mostram bem a produtividade e a expressividade desse tipo de neologismo (cf. IGNEZ, 2009).

Uma outra característica peculiar da neologia literária é sua exclusividade ao texto literário. Dificilmente, criações semelhantes a mostrada anteriormente entre no falar cotidiano ou em algum dicionário, contrariamente ao que acontece com os neologismos de outros textos, como os dos textos científicos, jornalísticos ou orais. Isso se deve, lógico, pela particularidade de cada neologismo que é singular, tais criações só significam em determinados contextos, marcam determinados autores, não possuem um fundo prático comunicativo. As criações literárias geralmente possuem um fim conotativo, emotivo e não comunicativo. Muito embora possua alguns semas gerais, mas a organização semântica de cada uma dessas unidades é particular e impede que seja empregada na comunicação geral (CARDOSO, 2013).

\section{Metodologia}

A seleção dos poemas de Ferreira Gullar para esta análise seguiu a ordem cronológica das publicações dos livros de poesias. Desse modo, as análises serão feitas em alguns poemas das obras $A$ Luta Corporal, de 1954, O Vil Metal, de 1960, Dento da Noite Veloz, de 1975 e Poema Sujo, de 1976. Os poemas escolhidos são aqueles em que se pode perceber, com maior nitidez, as criações neológicas de Gullar e naqueles em que o neologismo marca o caráter subjetivo do poeta. Essa escolha está pautada no pressuposto de que Gullar, em seus primeiros livros, tem maior preocupação com a linguagem e com o fazer poético, muito embora, com já observados em Serra e Costa (2012), a questão metaliterária é uma constante bastante pertinente em sua poesia. Adota-se o pressuposto de que Gullar possui três fases com relação a sua temática: a primeira fase, a experimentalista e de embate meta-artístico; a segunda, a fase demagógica e de luta partidária e a terceira e última fase, que seria a mais intimista. A publicação de três obras marca essas três fases: A Luta Corporal, marca a primeira, João Boa Morte, Cabra marcado para morrer, de 1962, marca a segunda e Barulhos, de 1987, marca a terceira fase. Cabe notar que boa parte dos livros escolhidos para análise encontram-se nas duas primeiras fases da obra gullariana, momento de vital de embate com questões que estejam externas ao poeta, como política, pobreza e ideologia.

Sendo desse modo, observa-se como o neologismo literário marca as atitudes de Gullar diante da vida e diante dos problemas sociais denunciados em sua poesia.

\section{Neologismo Literário na Poesia de Ferreira Gullar}

A análise dos poemas de Ferreira Gullar à luz da Teoria Neológica lança a atenção sobre um aspecto pouco estudado sobre a poesia do maranhense. É importante atentar que, como já mencionado, Gullar é um eximo experimentador da linguagem humana o que faz com que sua poesia, pelo menos na sua primeira fase produtiva, possua um cabedal de tesouros léxicos.

É em seus primeiros livros que Gullar deixa florescer seu caráter neológico. Com o intuito de desconstruir a linguagem, em busca de uma nova forma linguística, Gullar vai de encontro a uma sintaxe imposta pela língua, dando origem a sua primeira grande obra de impacto, o livro $A$ Luta Corporal, de 1954, onde o poeta infringe por um experimentalismo nunca dantes visto na poesia brasileira. No livro, Gullar trava uma luta (corporal) com a poesia transformando-a, utilizando, até se esgotar, o poder expressivo da palavra, até desintegrá-la. Nesse sentido, para Gullar, uma verdadeira vanguarda deveria inovar não somente nos temas, como fizeram os poetas do primeiro movimento Modernista no Brasil, mas também na forma, a poesia teria que ser reinventada, reorganizada e essa

Revista do GELNE, Natal/RN, Vol. 20 - Número 1: p. 136-149. 2018 
nova poesia, muito embora apresente formas pouco convencionais, era uma nova expressão diante do mundo. É para o que alerta Domingues (2007, p. 153, grifo original) ao relatar que "Esse livro é um verdadeiro laboratório de pesquisa sobre linguagem, pois “urge buscar outras formas". A leitura não só dos poemas, mas também dos textos críticos, revela a luta travada com a palavra".

O próprio Gullar, ao explicar o sentido do título do livro, revela o quanto a palavra é importante em seu poema:

Luta porque essa identificação do homem com a linguagem era uma aspiração e não uma realidade conquistada. Luta para transformar a linguagem num corpo vivo, vivo como o meu próprio corpo, denso como um ser natural, como um organismo. Essa tentativa me levou a violentar a sintaxe e os vocábulos a ponto de o poema se tornar quase ilegível. (GULLAR apud DOMINGUES, 2007, p.153)

Nesse sentido, no livro, a linguagem sofre alterações, os poemas são deslocados de seus lugares tradicionais, além de os temas abordados serem também diferentes. A poesia (a arte no total) é posta em questão. Tal embate e transformações apresentam um conjunto de neologismos literários, os quais apresenta-se seguidamente.

O primeiro tipo de neologismo criado por Gullar analisado será o fonológico. O Poeta, em seu percurso desconstruidor da linguagem, inaugura um grupo de elementos diferenciados, criações inéditas e inesperadas. Em Roçzeiral, é possível observar um conjunto de formações neológicas de difícil decodificação e de junções fonológicas inéditas em língua portuguesa, tratando-se, desse modo, de neologismos ex-nibilo:

Au sôflu i luz ta pompa inova'

orbita
FUROR
tô bicho
'scuro fo-
go

Rozal, ROÇAL

$\cdots$

MU

LUISNADO

VU

GRESLE RRA

Rra Rra

GRESLE

RRA

I ZUS FRUTO DU

DUZO FOGUARÉO

DOS OSSOS DUS

DIURNO

(...)

PALAVRA STÊRÇÃ

DEOSES SOLERTES PALAVRA

ADZENDA PALAVRA

POÉNDZO PALARVA

NÚ-

MERO FÓSSEIL

LE SOLÉLIE PÓe

ÉL FOSSIL PERFUME

LUMEM LUNNENi

Revista do GELNE, Natal/RN, Vol. 20 - Número 1: p. 136-149. 2018 


\section{U Z Z E N M \\ LA PACIÊNÇA TRAVALHA \\ LUZNEM}

O percurso criativo de Gullar o leva a construções novas, muito embora estranhas e sem algum conteúdo nocional em si mesma, mas que simbolizam um jogo literário extremamente complexo e novo. Tais formações, dentro do universo gullariano, sinalizam uma exaustividade expressiva, alcançada a partir de uma extrema e constante experimentação. Nesse âmbito, é válido lembrar o que nos alerta Cardoso (2013, p. 39) ao explicar que "As palavras mágicas não podem ser comuns, devem ser palavras especiais, pronunciadas num momento especial. São inéditas e têm um significado dentro do contexto”. É interessante observar nos versos de Gullar que há algumas palavras "inteiras", como bicho, palavra, outras podem ser vistas transformadas em outras ou flagradas em pleno processo de metamorfose, ou em forma de cruzamentos vocabulares, um tipo de neologismo sintagmático por composição, como Adženda, Roçal, Luisnado, Adženda. Por outro lado, os neologismos fonológicos, no poema, são em maior número. Além de em Roçzeiral, outras criações ex-nibilo podem ser observadas no livro O Vil Metal, de 1960, sobretudo no poema Um Crime na Flora.

Em O Inferno, onde pode-se flagrar um outro tipo de neologismo fonológico, que são as reduções silábicas, é possível um importante processo de recriação da comunicação. Ao retonar de sua guerra contra a linguagem, Gullar retoma ao reino das palavras e essas retomam as suas primeiras feições por meio do neologismo fonológico:

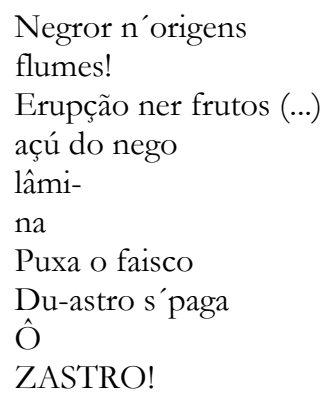

A onomatopeia, uma outra forma de neologismo fonológico, é um outro recurso utilizado por Gullar para demarcar, no Poema Sujo, a existência da locomotiva que levou o poeta e seu pai numa viagem pelo Pará:

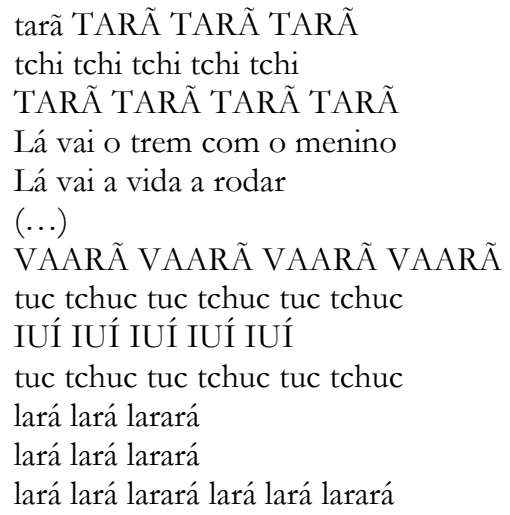

Vale notar uma outro trecho do Poema Sujo, onde Gullar cria, por meio de uma combinação das sílabas de palavras vale e tem, e por meio da organização do verso a página em branco, a ideia de movimento de um trem. 


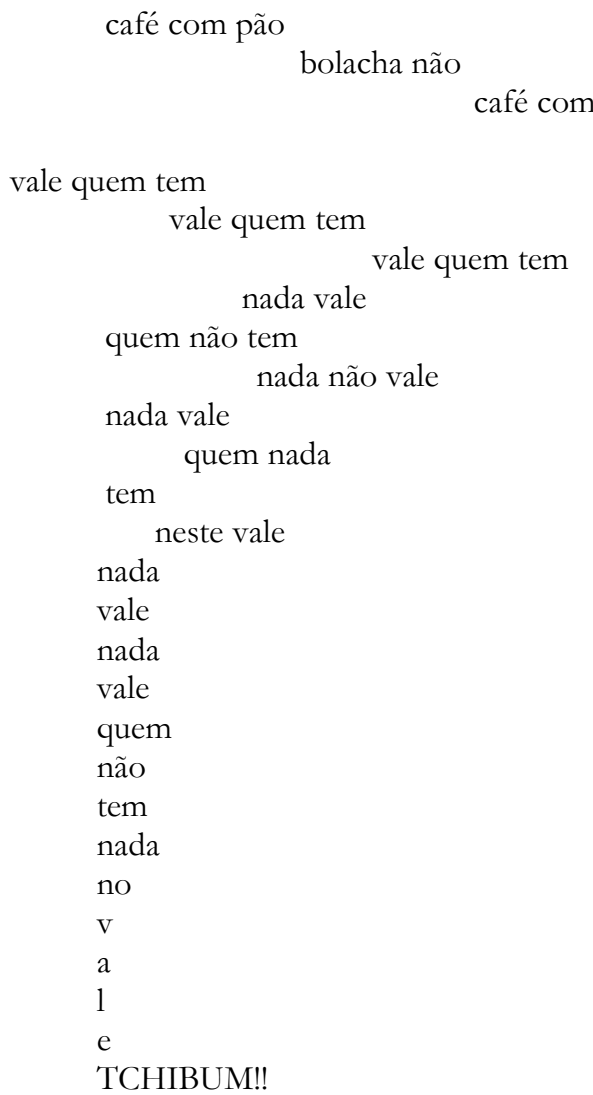

bolacha não

Cumpre atentar para o jogo semântico que há por trás da criação de um neologismo semântico. A disposição dos versos sugere uma confusão mental e espiritual no poeta. Essa disposição está de algum modo ligado à exploração de metais em algumas regiões do estado do Pará, onde a empresa Vale do Rio Doce, que é quem administra a via ferroviária da região, explora minério. A desagregação vocabular, notada nos últimos versos sugere que o fim daqueles que nada tem é o fundo do vale, o fundo do mar, o esquecimento, o descambo para o mar, grande agregador de massas d'água (que aqui, são tomadas como pessoas que nada têm), o que nos sugere o uso de TCHIBUM!! e a quebra do poema.

Com relação ao neologismo semântico, Gullar apresenta uma infinidade de poemas, sobretudo, a partir de metáforas. Nesta exposição, será apresentado apenas o poema Galo Galo, com o qual Gullar, segundo Becker (2012), compara o poeta a um galo. Segue um trecho do poema:

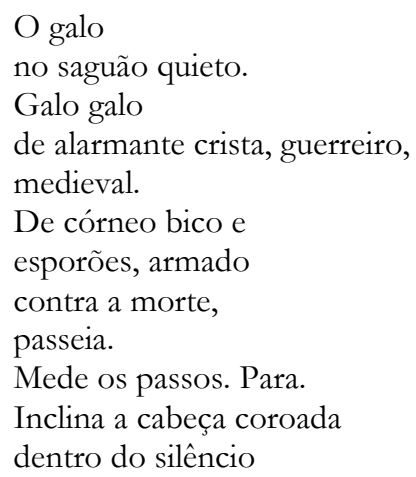




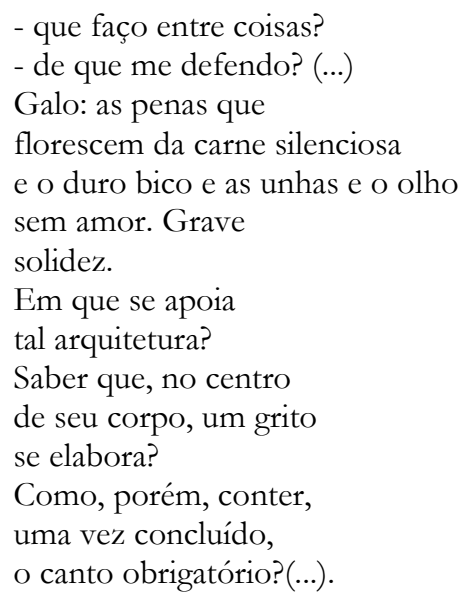

No poema, o galo poeta possui um grito preso em sua garganta, o som está preso no centro de seu corpo, um grito estranho que só o poeta compreende. A vanguarda ultrajante, experimentada por Gullar, segundo Becker (idem), fazia com que o poeta apresente-se solitário e, muitas vezes, sem ecos. Becker (2012, p 281, grifo do original) explica a densa metáfora utilizada pelo poeta:

(...) o poeta se compara ao galo solitário, extraviado num "saguão do mundo". Dessa forma, a alternativa que resta ao poeta é cantar apenas para si mesmo, acreditando que tal canto se deve a uma necessidade interna incontestável, e esquece o mundo em torno, no qual seu canto já não encontra eco.

Os neologismos semânticos criados pela metáfora são os mais abundantes na poesia de Gullar, desse modo, como não é o propósito deste estudo esgotar os exemplos neologismo semântico utilizados por Gullar, mas sim apresentá-los, sugere-se a leitura de outros poemas como Exercício de relax (Barulhos) A fala (Luta Corporal), cantada (Dentro da Noite Veloz) entre inúmeros outros, nos quais o neologismo semântico, que é natural do texto literário (mas não só dele!) aparecem com grande vigor.

Outro tipo de neologismo também utilizado por Gullar nas obras investigadas é o neologismo sintagmático, "produto da derivação e da composição sintagmática" (BARBOSA, 2001, p. 41). Em O Inferno, de A Luta Corpora, O poema, como já mencionado, é uma tentativa de retorno à linguagem humana, ou pode ser também, uma reelaboração da linguagem, uma luta entre o artifício poético e o da linguagem; o inferno é o reino da palavras onde o eu-lírico, solitário, luta contra as leis que governam o ato poético, ou como afirma no próprio poema "Estamos no reino da palavra, e tudo que aqui sopra é verbo, e uma solidão irremesível”. No retomar da linguagem, destruída em Roçžeiral, Gullar utiliza-se da neologia sintagmática para escalar do inferno verbal. Confundindo-se com a própria linguagem, Gullar cria neologismos a partir de composição por subordinação, como em "eu-Língua" e "conta-força" que, no poema, funcionam como denotadores de uma resistência, na batalha contra a linguagem:

MAS EU, NÃO OUTRO, E MINHA LINGUAGEM É A REPRESENTAÇÃO DUMA DISCÓRDIA (...)

$$
\begin{gathered}
\text { LUETI PARA TE LIBERTAR } \\
\text { eU-LINGUA } \\
\text { MAS EU SOU A FORÇA E } \\
\text { A CONTRA-FORÇA } \\
\text { MAS EU NÃO SOU A FORÇA } \\
\text { E NEM A CONTRA-FORÇA }
\end{gathered}
$$

Em O Quartel (Dentro da Noite Veloz), Gullar também cria alguns neologismos sintagmáticos para denotar o cansado e o enfado dos soldados de um quartel, no Rio de Janeiro, que solitários 
acabam-se numa rotina mortal. Gullar cria as palavras "zostrabalhosehàzumsonoinicial”, "canto canto" e "canto pó".

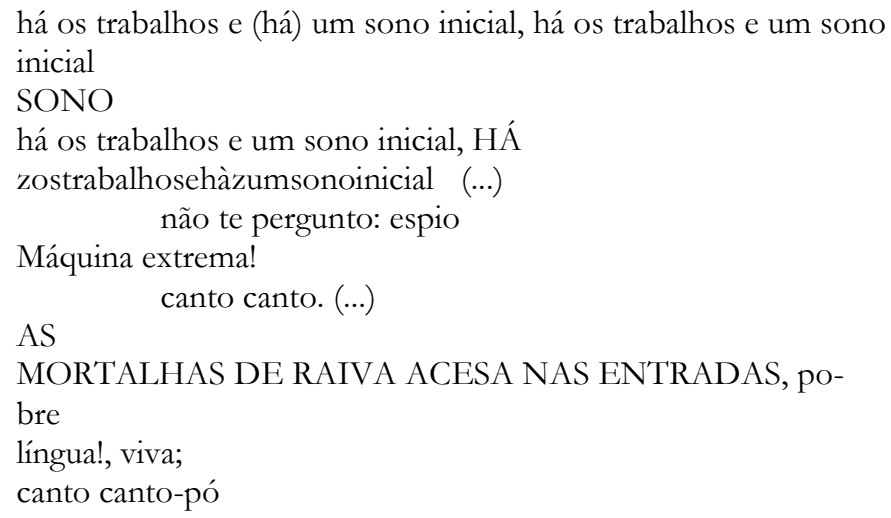

No poema, onde os soldados do quartel digladiam-se para ver quem tem o canto mais belo, Gullar mais uma vez, toca no tema da linguagem, comparando-a a um toque de uma trombeta solitária. No final, um galo solitário (galo poeta) é quem figura com o canto mais belo, o "canto canto", um substantivo agindo na função de adjetivo, isso para dar um sentido mais amplo a canto, não sendo apenas um canto, mas o canto do poeta. A junção das orações "há os trabalhos, há um sono inicial, há os trabalhos e um sono inicial", dão origem a um neologismo formado por sintagmação dessas orações "zostrabalhosehàzumsonoinicial”, que significa o cansaço e a rotina dos soldados do quartel, que de sempre fazerem as mesmas coisas, acabam juntando, automaticamente, as palavras, num sinal de intermitência e fadiga. O último parágrafo do poema também traz uma formação digna de apreciação, que é "canto canto-pó”: esse neologismo simboliza o silêncio do galo poeta, é a ida ao pó do canto daquele galo que canta tão formidavelmente.

Outro poema de Gullar que nos dá inúmeros exemplos de neologismos sintagmáticos é o Poema Sujo. No trecho do poema em que Gullar observa a si mesmo e faz uma análise de si e de sua condição no mundo, de sua importância para a criação da história, numa perspectiva materialista, Gullar questiona-se acerca de seu lugar no espaço, de sua forma como cidadão do mundo. Gullar, em um trecho de Poema Sujo, onde embarca numa reflexão profunda acerca do fato de que sua existência está atrelada a seu corpo, toma o lugar de um eu-lírico e retrata-se no poema, dando suas características físicas: "meu corpo, que deitado numa cama vejo, como um objeto no espaço, que mede 1, 70, e que sou eu, essa coisa deitada, barriga, pernas, pés, com cinco dedos cada um (...)”. Mais uma vez, Gullar utiliza-se da repetição de dois substantivos no sentido de conotar a ideia do corpo poético, por meio da palavra "corpo corpo", que como em Galo Galo, retoma o poético, o eu-lírico. Observa-se uma briga entre as personagens do eu-lírico e do poeta; Gullar sugere uma intercalação entre a realidade vivida por Ferreira Gullar, de temor da morte, e o sentimento poético do eu-lírico, dualidade que dá o tom em todo o poema e que pode ser observado no primeiro verso desse trecho de Poema Sujo.

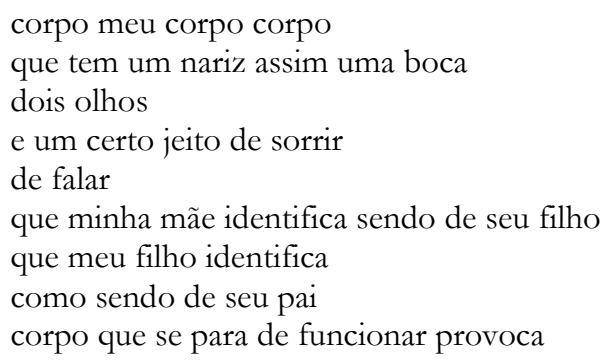


um grave acontecimento na família sem ele não há José de Ribamar Ferreira não há Ferreira Gullar.

Outras criações curiosas ligadas ao corpo do poeta aparecem no trecho seguinte, que ainda estão no clima de disputa do eu-lírico e o poeta Ferreira Gullar. "corpo-facho", "corpo-fátuo" e "corpo-fato" são formações que dão ideia do fogo, do calor, de vida, o corpo do poeta, que apesar de estar em perigo iminente da morte, pulsa cheio de vida (fogo), de prazer, prazer momentâneo, por isso o corpo é fátuo, é facho (chama de fogo), é fato (luz), é uma chama que apesar de ardente, pode apagar a qualquer momento. Em outra construção neológica sintagmática que vai nesse mesmo sentido, fogo-vida-prazer, ainda no mesmo trecho, é "corpo-falo", trazendo a ideia do fogo adjungido a ideia de prazer sexual, que, como uma chama, pode ser momentânea. Segue o trecho onde pode-se observar esses neologismos sintagmáticos gullariano.

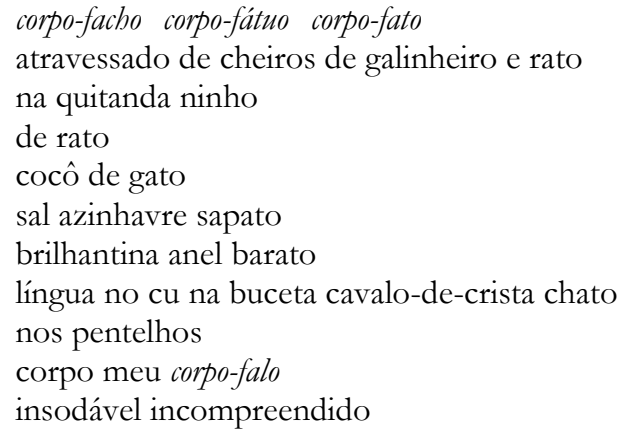

O eu-lírico segue contando suas sensações e falando de seu mundo de sentidos, mas agora, esse mundo se expande para uma galáxia, por estar aberto a todos os elementos a seu redor e por ser amplo, ideia sugerida com a criação neológica "corpo-galáxia".

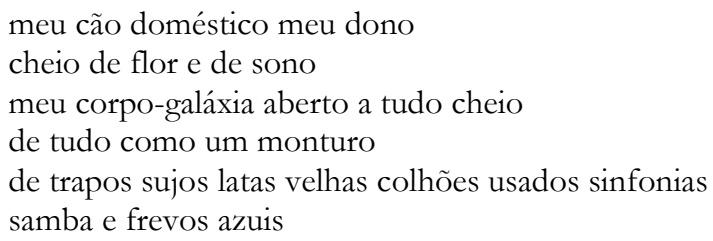

Toda tensão da disputa entre o eu-lírico e o poeta resulta em um rojão de neologismos sintagmáticos criados a partir de sufixações que sugerem uma união entre as duas partes. No trecho que segue, Gullar faz com que a história de José de Ribamar Ferreira (nome completo do poeta) se misture com as sensações do eu-lírico e juntos mostrem o quanto o centro de sua sensações (seu corpo) carrega de sua identidade. Essas ideias podem ser observadas nos neologismos por derivação sufixal "sanluisense", "ferreirense", "newtoniense", "alzirense".

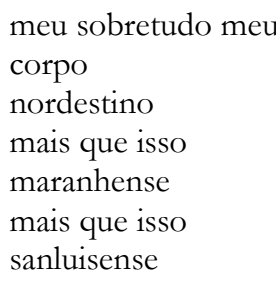


mais que isso

ferreirense

newtoniense

alzirense

meu corpo nascido numa porta-e-janela da Rua dos Prazeres pais do poeta.

Cumpre notar que Newton Ferreira e Alzira Goulart (dona Zizi) é como eram chamados os

Por fim, observa-se alguns estrangeirismos que aparecem na poesia Gullariana. Em Fora da Luг (O Vil Metal), Gullar utiliza-se de um galicismo. No poema, Gullar deixa entrevisto uma relação sexual com uma donzela, e o fogo é o desejo do eu-lírico pela moça. O eu-lírico, após o coito, descansa e admira a jovem donzela. A forma "bonjur, Madame!" sugere sutileza e frescura da mulher que desperta ao lado do amado.

de tal fogo tal facho trabalhado
às portas desse homem a leste dele
Fogo poeira pó polvora acessa
na epiderme comum. Bonjour, Madame!

No poema Por Você, Por mim (Dentro da Noite Veloz), Gullar lança mão de inúmeros anglicismos para tratar da invasão dos Estados Unidos ao Vietnã e da resistência do povo aos americanos. O eu-lírico, em uma manhã carioca, se questiona: "Que se passa em Huê? em Da Nang? No Delta do Mekong? Te pergunto, nesta manhã de abril no Rio de Janeiro, te pergunto, que se passa no Vietnam?”. A partir dessas indagações, o eu-lírico se questiona acerca da relatividade da vida, o impressionante fato de que no Rio de Janeiro, naquele mesmo momento, o eu=lírico percebia a dualidade da vida, vistas que diante de sua janela as pessoas vivem tranquilas e normalmente e no Vietnam, as pessoas estariam lutando para sobreviver. Nesse rojão de indagações que é o poema Por Você, Por Mim, Gullar utiliza-se de anglicismos para marcar a presença americana no pais asiático:

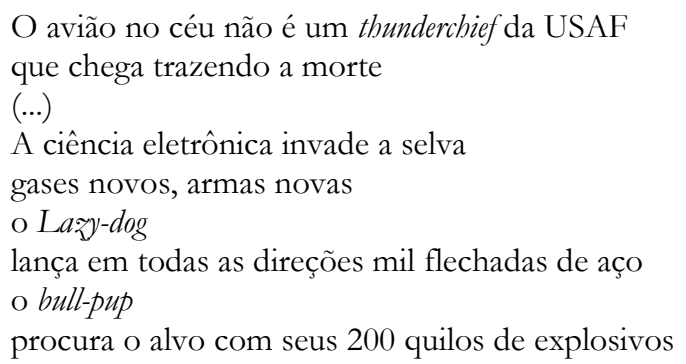

No poema Dentro da Noite Veloz (Dentro da Noite Veloz),o eu-lírico comemora a revolução cubana e descreve, romanticamente, a ação dos guerrilheiros companheiros de Fidel Castro e Che Guevara. Na descrição, Gullar escreve inúmeros trechos em língua castelhana, levando o leitor em uma atmosfera da ilha cubana:

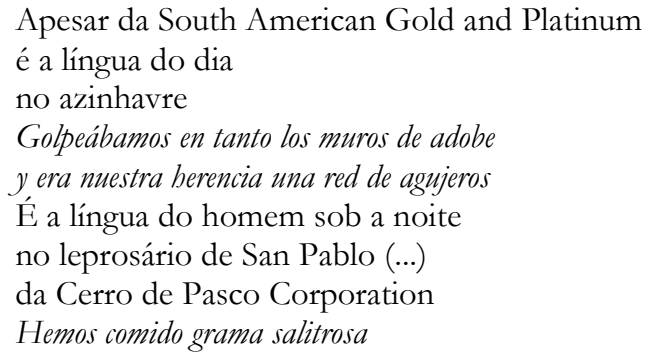


piedras de adobe largatijas ratones

tierra en polvo y gusanos

Outro poemas de Gullar trazem galicismo, anglicismos, latinismos entre outros empréstimos, sendo em grande maioria das línguas latinas (espanhol e francês mais constantemente) e do inglês.

\section{CONSIDERAÇÕES FINAIS}

Como se pôde observar ao longo deste estudo, Gullar é um poeta que lança mão de alguns neologismos estilísticos para tratar de seus temas. A palavra neológica carrega consigo sentidos particulares, sentidos que muitas vezes as palavras disponíveis no vocabulárionão conseguem atingir.

Observou-se que cada neologismo criado por Gullar está atrelado a um momento específico, há um dizer, um pensar por detrás de cada nova formação, tais formações evidenciam um universo neológico gullariano. Ficou evidente também que em sua primeira obra, A Luta Corporal, o experimentalismo deixou importantes criações neológicas que marcaram os primeiros momentos da linguagem do autor. Desse modo, fica evidente que as criações de Gullar são, na verdade, um cosmo especial, único, específico e que demarcam bem a trajetória do poeta maranhense.

É importante cumprir que o corte temporal - ter elegido só as primeiras duas fases de criações de Gullar - mostrou-se bastante interessante, mas que deixou uma lacuna que poderá ser preenchida em estudos subsequentes para saber se essas criações continuam tão vivas como em suas primeiras obras, em sua fase de busca pela palavra poética. No entanto, os resultados apresentados, mostram que Gullar foi (e continua sendo) um importante poeta inovador, como todo bom poeta vanguardista.

É válido notar também que o universo gullariano é um todo vivido com a palavra. Gullar, como se observou no poema O Inferno, vive no mundo da palavra e a construção (e desconstruções) dela é algo que interessa ao poeta no momento da expressão de seu pensamento, sensações e formas de ver a realidade; desse modo, é possível concluir que o neologismo literário é algo que também caracteriza a poesia do mestre maranhense.

\section{REFERÊNCIAS BIBLIOGRÁFICAS}

ALVES, I. M. Neologismo: criação lexical. São Paulo: Ática, 2007. 93p.

BARBOSA, M. A. Da neologia à neologia na Literatura. In. OLIVEIRA, A. M. P.; ISQUERDO, A. N. (Orgs). As ciências do léxico: Lexicologia, Lexicografia e Terminologia. $2^{a}$ Ed. Campo Grande: EdUFMS, 2001. p 33-51.

BECKER, P. R. Os limites da linguagem na poesia de Ferreira Gullar. Desenredo (PPGL/UPF), v. 8, p. 275-289, 2012.

CABRÉ. M. T. La neologia, campo disciplinar y aplicado: utilidad y problemas en el trabajo neológico de los observatorios. In. ALVES, I. M. (Org.). Neologia e Neologismos em diferentes perspectivas. São Paulo: Paulistana, 2010. p 13-33.

CARDOSO, E. A. A criação neológica estilística. In. ALVES, I. M. (Org.). Neologia e Neologismos em diferentes perspectivas. São Paulo: Paulistana, 2010, p. 229-249.

. Drummond: um criador de palavras. São Paulo: Annablume/ FAPESP, 2013. 312p

DOMINGUES, T. C. A. Ferreira Gullar e a palavra poética. Revista Verbo de Minas: Letras. v 6, n
$11 / 12$,
$\mathrm{p}$
151-182,
2007.
Disponível
em:

Revista do GELNE, Natal/RN, Vol. 20 - Número 1: p. 136-149. 2018 
http://www.cesif.br/revistas/verbo de minas/edicoes/2007/12 Ferreira Gullar a a palavra.pdf acesso em: 13/12/2013

GUILBERT, L. La créativité lexicale. Paris: Larousse, 1975.

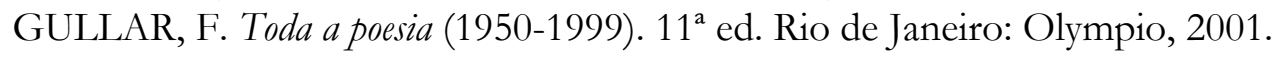

IGNEZ, A. F. A criação lexical em Galáxias, de Haroldo de Campos. In: GARCIA, B.R.V.; CUNHA, C.L.; PIRIS, E.L.; FERRAZ, F.S.M.; GONÇALVES SEGUNDO, P.R. (Orgs.). Análises do Discurso: o diálogo entre as várias tendências na USP. São Paulo: Paulistana Editora, 2009. Disponível em: http://www.epedusp.org acesso em: 12/10/2013

MACEDO, D. A. . Traços estilísticos de Ferreira Gular em Poema Sujo, 1976. Mafuá (Florianópolis), v. 02, 2004.

MOURA, G. Ferrera Gullar: entre o espanto e o poema. Rio de Janeiro: Relume do Mará, 2001.

SERRA, L.H. COSTA, J.D.C. O poema é uma coisa que não tem nada dentro: reflexões metaliterárias na poesia de Ferreira Gullar. Revista Terra Roxa e Outras Terras. n 2, v 23, 2012. p. 44-57. Disponível em: http://www.uel.br/pos/letras/terraroxa/g pdf/vol23/TRvol23d.pdf acesso em: $13 / 10 / 2013$

Recebido em 28/12/2017

Aceito em 24/5/2018 